\title{
Cyclooxygenase inhibitor induces the upregulation of connexin-43 expression in $\mathrm{C6}$ glioma cells
}

\author{
LI-JUAN QIN $^{1}$, YONG-SEN JIA ${ }^{2}$, YI-BING ZHANG ${ }^{1}$ and YIN-HUAN WANG ${ }^{1}$ \\ ${ }^{1}$ Department of Physiology, School of Basic Medical Sciences; ${ }^{2}$ College of Traditional Chinese Medicine, \\ North China University of Science and Technology, Tangshan, Hebei 063000, P.R. China
}

Received November 25, 2015; Accepted February 2, 2016

DOI: 10.3892/br.2016.613

\begin{abstract}
The present study was performed to determine whether aspirin, a cyclooxygenase (COX) inhibitor, has an effect on the expression of connexin 43 (Cx43) in C6 glioma cells. Using an in vitro glioma invasion model, the expression of Cx43 protein in C6 cells was significantly increased following aspirin treatment at a dose of $8 \mathrm{mmol} / 1$ for 30,60 and $120 \mathrm{~min}$ via western blot analysis. The peak value of the $\mathrm{Cx} 43$ expression was observed in C6 cells after $120 \mathrm{~min}$ of aspirin treatment, which was significantly reduced by prostaglandin E2 (PGE2). In addition, aspirin also significantly increased the gap junction intercellular communication (GJIC) activity and reduced glioma invasion, which was induced by PGE2. This led to the conclusion that the aspirin-induced glioma invasion decrease may be associated with the increased expression of $\mathrm{Cx} 43$ protein and formation of GJIC.
\end{abstract}

\section{Introduction}

Brain glioma is one of the most common central nervous system diseases, which is invariably associated with a high mortality (1). Gliomas are characterized by an intense local invasiveness that limits the usefulness of preferred surgical treatment $(2,3)$. Therefore, reducing the invasiveness of glioma will allow for a significant treatment option for brain tumors.

Lan et al (4) demonstrated that aspirin is a potent antitumor agent through the inhibition of the $\beta$-catenin signaling pathway in glioma cells. However, the mechanism of aspirin-induced glioma invasion decrease remains to be elucidated.

Glioma, an aggressive form of adult brain tumor, is difficult to treat due to its invasive nature. The current treatment for glioma is resection of the tumor, followed by chemotherapy and radiation therapy $(5,6)$. Even with such radical treatments,

Correspondence to: Dr Li-Juan Qin, Department of Physiology, School of Basic Medical Sciences, North China University of Science and Technology, 57 South Road of Construction, Tangshan, Hebei 063000, P.R. China

E-mail: qinlj20012003@163.com

Key words: cyclooxygenase, glioma, prostaglandin, connexin 43, gap junction intercellular communication patients with glioma suffer from recurring tumors that arise due to the invasive nature of glioma cells. In addition to the histological changes, several molecular changes occur in the process of glioma genesis (7-9). Previous studies have shown a decrease the expression of the gap junction protein connexin 43 (Cx43) in gliomas (10-13). Cx43 is the major gap junction protein in astrocytes; gap junctions directly link the cytoplasm of adjacent cells, thus establishing a glial syncytium.

Prostaglandin (PG) has been shown to promote tumor angiogenesis and induce cell proliferation, suggesting that glioma invasion may be associated with PG. In addition, several experimental and human tumors synthesize prostanoids (14-16), which can be increasingly produced during tumor development. These cyclooxygenase (COX) metabolites may influence the physiopathological processes associated with tumor development. The capacity of tumors to grow, disseminate and influence host homeostasis has, in certain cases, been associated with the production of elevated amounts of specific prostanoids.

Aspirin, a non-steroidal anti-inflammatory drug, is used widely to relieve pain, fever and peripheral inflammation. Low-dose aspirin (75-150 mg/day) is recommended for long-term prophylaxis of thrombotic events such as heart attacks and strokes, while a higher dose $(1 \mathrm{~g})$ has analgesic and antipyretic effects (17). Aspirin irreversibly inhibits COX-1, which converts arachidonic acid (20:4n-6) to PG endoperoxides, and thus reduces PG formation (18).

Based on the aforementioned results, we hypothesize that aspirin could reduce the glioma invasion through regulating the expression of $\mathrm{Cx} 43$, and this process is mediated by PGE2 production. To test the hypothesis, we utilized an in vitro glioma invasion model and investigated the effects of aspirin to reduce the glioma invasion. In addition, whether aspirin had an effect on the expression of Cx43 at a protein level was examined by western blot analysis, and the function of gap junction intercellular communication (GJIC) was tested by the scrape-loading dye transfer technique method in C6 cells.

\section{Materials and methods}

C6 cell culture. Rat C6 glioma cells (obtained from the Cell Center Department of the Chinese Academy of Medical Sciences, Beijing, China) were grown in Dulbecco's modified 
Eagle's medium (DMEM) (Gibco, Thermo Fisher Scientific, Inc., Dreieich, Germany) supplemented with $15 \%$ heat-inactivated fetal bovine serum (FBS; cat. no. 10270-106; Hyclone, Thermo Fisher Scientific, Inc., Shanghai, China), $100 \mathrm{U} / \mathrm{ml}$ penicillin and $100 \mu \mathrm{g} / \mathrm{ml}$ streptomycin under standard culture conditions. When the cells reached confluency, the medium was aspirated and fresh serum-free medium was added to the cells for $12 \mathrm{~h}$. The cells were subsequently washed once with sterile phosphate-buffered saline (PBS), and fresh serum-free medium was added. The following experiments were carried out for the cells treated with $8 \mathrm{mmol} / \mathrm{l}$ aspirin (Sigma Resources and Technologies, Inc., Santa Clara, CA, USA) for 30,60 and $120 \mathrm{~min}$.

Measurement of PGE2. An enzyme-linked immunosorbent assay was performed to measure the level of PGE2 expression using the appropriate kits from HyCult Biotechnology (Uden, The Netherlands) and R\&D Systems, Inc. (Minneapolis, MN, USA), following the manufacturer's protocol. All the assays were performed in triplicate, and data are shown as mean \pm standard error of the mean.

Cx43 protein extraction and western blot analysis. The effect of aspirin on $\mathrm{Cx} 43$ protein expression was analyzed using western blot analysis. Protein homogenates of the C6 cells samples were prepared by rapid homogenization in 10 volumes of lysis buffer. Samples were centrifuged at $17,000 \mathrm{x} g$ for $1 \mathrm{~h}$. The protein concentration of soluble materials was determined by the Coomassie G250 binding method. The protein lysates (12 $\mu \mathrm{g}$ per lane for each sample) were fractioned on $12 \%$ SDS-polyacrylamide gels, followed by transfer to nitrocellulose membranes (Merck Millipore, Darmstadt, Germany). The membranes were blocked in blocking buffer (5\% non-fat dairy milk dissolved in Tris-buffered saline with Tween-20) overnight at $4{ }^{\circ} \mathrm{C}$. The blots were subsequently incubated with rabbit polyclonal antibody anti-Cx43 (dilution 1:400; cat. no. sc-9059; Santa Cruz Biotechnology, Inc., Santa Cruz, $\mathrm{CA}, \mathrm{USA}$ ) for $2 \mathrm{~h}$. The Cx43 protein bands on these immunoblots were visualized using the enhanced chemiluminescene kit (Boster Inc., Wuhan, China). The Cx43 protein bands and $\beta$-actin bands were scanned using the Bio-Rad Gel Doc ${ }^{\text {TM }}$ XR+ Gel imaging system (Bio-Rad, Berkeley, CA, USA), and integrated density values (IDVs) were calculated by the Quantity One software and normalized with that of $\beta$-actin.

GJIC activity. The scrape-loading dye transfer technique is a method to evaluate GJIC activity by calculating the number of cells containing the dye or measuring the distance of dye permeation through the gap junctions. Glioma cells were digested into single cells in $10 \mathrm{mg} / \mathrm{ml}$ collagenase I at $37^{\circ} \mathrm{C}$ overnight and $0.25 \%$ trypsin-EDTA at room temperature for 2 min. Glioma cells were cultured in DMEM/medium supplemented with 10\% FBS and an antibiotic mixture (penicillin $100 \mathrm{U} / \mathrm{ml}$ and streptomycin $100 \mu \mathrm{g} / \mathrm{ml}$ ) at $37^{\circ} \mathrm{C}$ in a humidified atmosphere containing $5 \% \mathrm{CO}_{2}$. Aspirin was added to the culture medium for 30, 60 and $120 \mathrm{~min}$ when the cell densities had reached $\sim 70 \%$ confluence. Subsequent to washing the cells with PBS three times, 10 scrapes were made through the confluent cells with a sterile pipette tip in the presence of warm PBS containing $1 \mathrm{mg} / \mathrm{ml}$ lucifer yellow. The cells were further

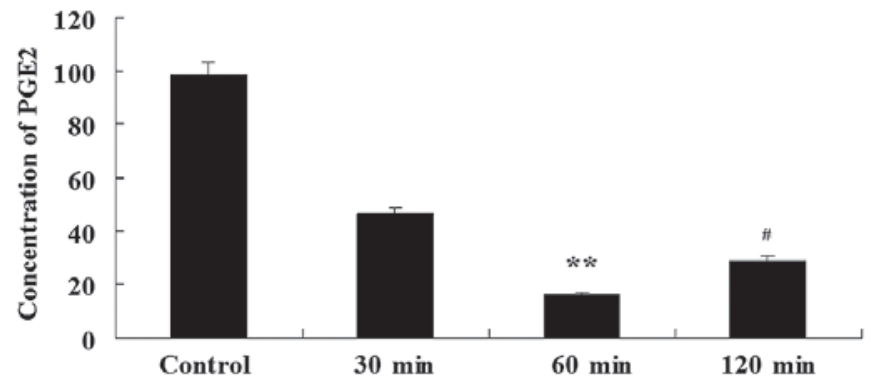

Figure 1. Concentration of PGE2 assessed by an enzyme-linked immunosorbent assay in the control and aspirin-treated groups $(8 \mathrm{mmol} / 1$ for 30 , 60 and $120 \mathrm{~min})$. Data are presented as mean \pm standard deviation $(\mathrm{n}=15$, each). ${ }^{* *} \mathrm{P}<0.01$ and ${ }^{\#} \mathrm{P}<0.05$ vs. the control group. PGE2, prostaglandin E2.

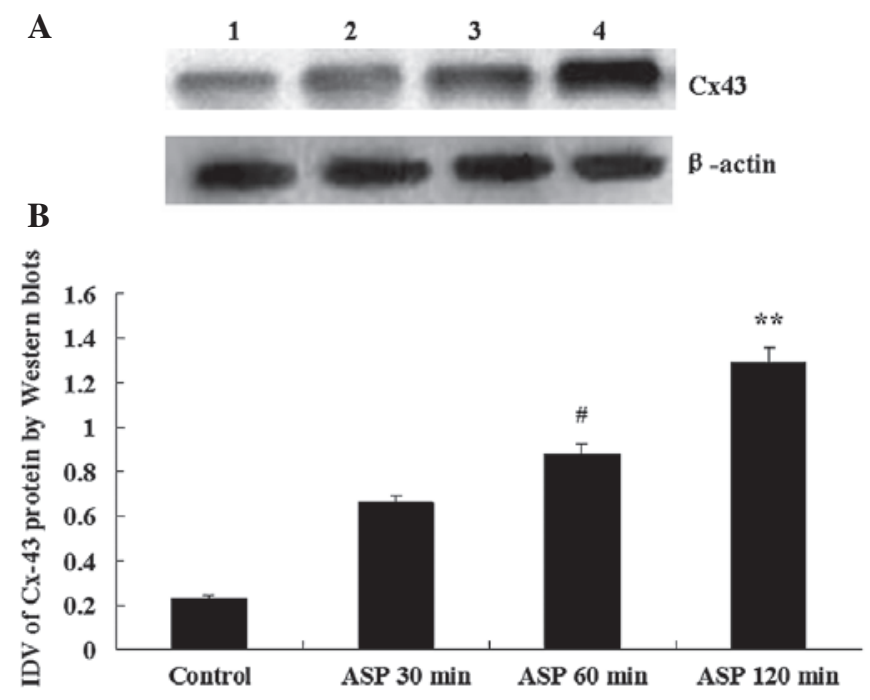

Figure 2. Effects of aspirin treatment on the $\mathrm{Cx} 43$ protein expression levels in the C6 cells at 30,60 and $120 \mathrm{~min}$. (A) Representative western blots illustrating the differences in the bands of Cx43. Lane 1, control group; lane 2, $30 \mathrm{~min}$ aspirin-treated group; lane 3,60 min aspirin-treated group; lane 4, $120 \mathrm{~min}$ aspirin-treated group. (B) Changes of the relative IDVs of Cx43 ( $\mathrm{n}=15$, each). ${ }^{* *} \mathrm{P}<0.01$ and ${ }^{\#} \mathrm{P}<0.05$ vs. the control group. $\mathrm{Cx} 43$, connexin 43 ; ASP, aspirin; IDV, integrated density value.

incubated at $37^{\circ} \mathrm{C}$ and with $5 \% \mathrm{CO}_{2}$ for $5 \mathrm{~min}$. Following this, lucifer yellow was removed, the cells were washed with PBS three times and they were fixed with $4 \%$ paraformaldehyde in PBS. The diffusion length of fluorandiol in gliomas was measured under a laser scanning confocal microscope (Olympus, Tokyo, Japan). GJIC activity was expressed as the mean diffusion length.

In vitro invasion assay. The C6 cells were resuspended in DMEM containing $15 \%$ fetal calf serum to obtain a concentration of $10^{7}$ cells $/ \mathrm{ml}$ and seeded $\left(10^{6}\right.$ cells/well) in the upper compartments for $120 \mathrm{~min}$; the $\mathrm{C} 6$ cells that migrated to the lower compartment were counted under a light microscope (Olympus). The experiments were performed in triplicate, and migration was determined by calculating the number of migrating cells.

Statistical analysis. Results are presented as the mean \pm standard deviation. One-way analysis of variance (ANOVA) was used to compare the group differences in the measurements of 

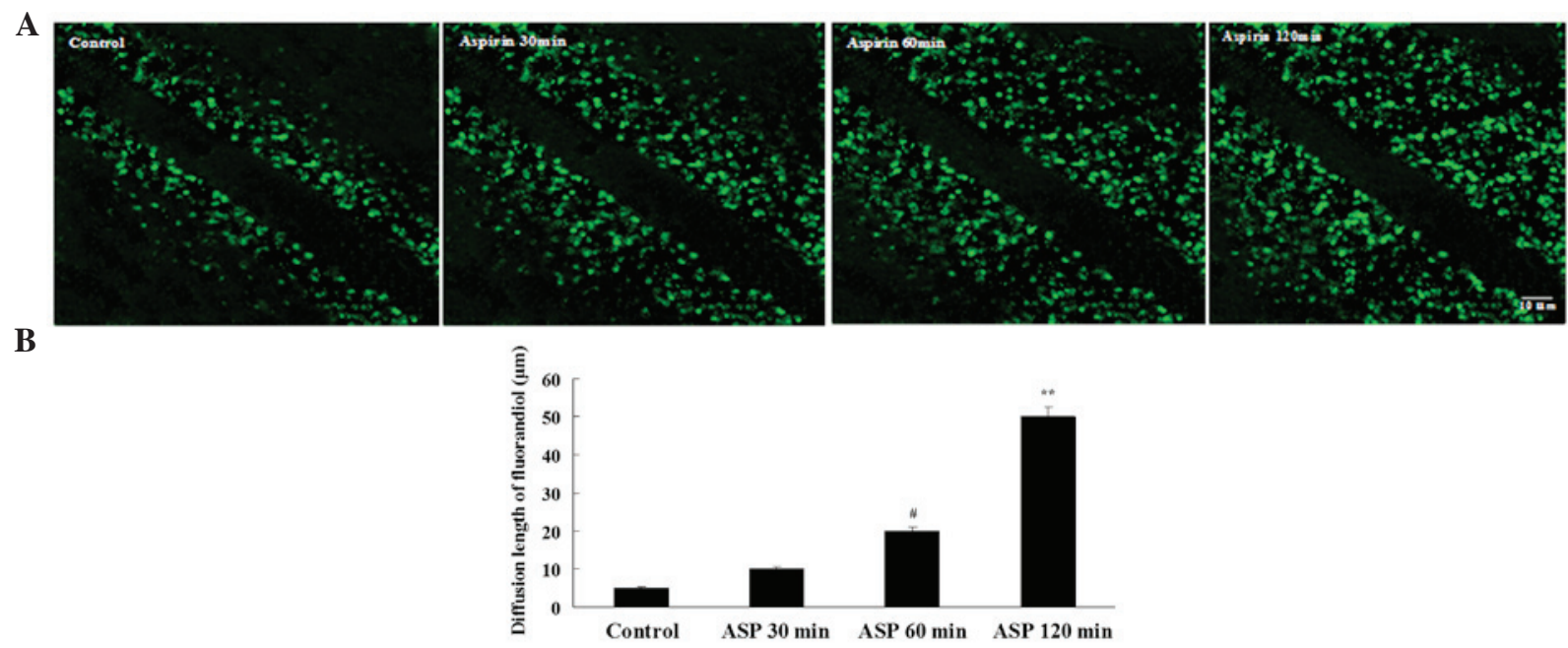

Figure 3. ASP treatment enhances GJIC function in C6 cells. Cultured C6 cells were treated with aspirin for 30, 60 and 120 min, following which aspirin was replaced with $1 \mathrm{mg} / \mathrm{ml}$ lucifer yellow and the scrape-loading dye transfer assay was performed as described. (A) Lucifer yellow transfer through the gap junction was enhanced significantly following aspirin treatment. (B) Quantitative analysis of GJIC function of C6 cells. ${ }^{* *} \mathrm{P}<0.01$ and ${ }^{\#} \mathrm{P}<0.05$ vs. the control group. ASP, aspirin; GJIC, gap junction intercellular communication.

Cx43 protein. Dunnett's post hoc tests were applied to compare specific group differences when the ANOVA revealed a significant difference. For other measurements, the data were assessed using paired Student's t-test.

\section{Results}

Relative levels of PGE2 from C6 cells. The content of PGE2 in the experimental groups was 2.12-6.05-fold lower compared to the control group; therefore, aspirin significantly enhanced the downregulation of PGE2. Specifically, aspirin decreased PGE2 after $60 \mathrm{~min}$ of treatment. The relative levels of PGE2 in the control group, and the 30, 60 and $120 \mathrm{~min}$ aspirin groups were $98.24 \pm 1.23,46.21 \pm 1.32$, $16.47 \pm 2.31$ and $29.05 \pm 1.98 \mu \mathrm{g} / 1$, respectively (Fig. 1). This demonstrated that aspirin has a direct inhibitory effect on the PGE2 level in glioma.

Aspirin induces overexpression of Cx43 proteins in C6 cells. In C6 cells infused with sterile saline (control group), the level of $\mathrm{Cx} 43$ expressed was low. Compared with the control group, the expression of $\mathrm{Cx} 43$ protein was markedly increased at three time-points following aspirin treatment. The IDVs of $\mathrm{Cx} 43$ at control group, 30, 60 and 120 min group were $0.238 \pm 0.058$, $0.669 \pm 0.055,0.886 \pm 0.065$ and $1.292 \pm 0.048$, respectively. The largest IVD was at $120 \mathrm{~min}$ after aspirin treatment (Fig. 2).

Aspirin enhances GJIC activity in C6 Cells. Dye transfer is a commonly used method to evaluate GJIC activity by calculating the number of dye-labeled cells or measuring the gap junction dye permeation. To determine if the increases in $\mathrm{Cx} 43$ protein are associated with the changes in GJIC activity, the cells were treated with aspirin for 30,60 and $120 \mathrm{~min}$, respectively, and the dye transfer between neighboring cells was evaluated. Aspirin increased the fluorescent yellow diffusion distance and the peak value at $120 \mathrm{~min}$, suggesting that aspirin can enhance the communication function of the gap of glioma cells (Fig. 3).

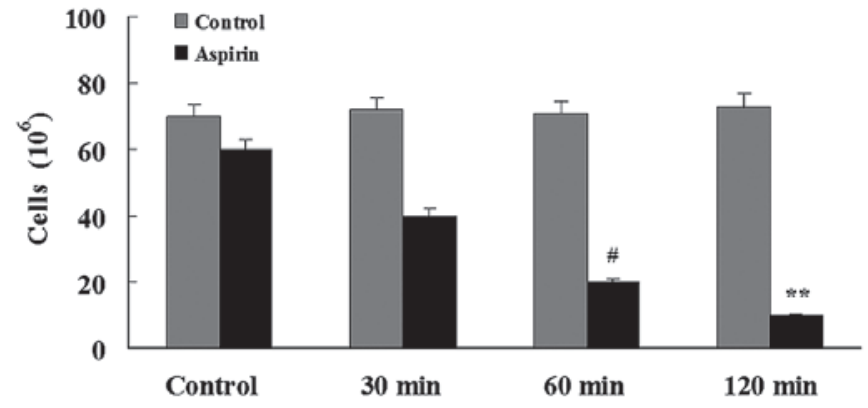

Figure 4. ASP induces a reduction in glioma invasiveness. C6 cells were subjected to aspirin treatment for different times and were compared with the control. Data are mean \pm standard deviation. ${ }^{* *} \mathrm{P}<0.01$ and ${ }^{\#} \mathrm{P}<0.05$ vs. the control group. ASP, aspirin.

Glioma invasion. The percentage of migrating cells was 1.6- to 4.1-fold lower in the aspirin-treated groups compared to the control group. Aspirin significantly reduced the number of migrating C6 cells after 120 min (Fig. 4).

\section{Discussion}

Inflammation has emerged as a major factor promoting cancer development and supporting cancer progression. However, inflammation can also have cancer-inhibitory effects (19-22). Inflammatory mediators can be produced by the stroma, by tumor-infiltrating leukocytes or directly by the cancer cells themselves. Prominent among tumor-sustaining mediators is PGE2, a prostanoid lipid associated with enhancement of cancer cell survival, growth and migration (23). COX-1 and -2, enzymes that are critical for the production of PGE2, are often overexpressed in colorectal, breast, stomach, lung and pancreatic cancers (24). Whether glioma similarly express abnormal levels of COX-2 remains to be elucidated. Castelli et al (25) reported that glioma can secrete PGE2. The present results showed that the expression of PGE2 and COX-2 in C6 cells were significantly higher compared to those in astrocytes. 
The C6 glioma cell line has been widely used in the cellular and molecular characterization of glial cells. One of the well-known characteristics of astrocytes concerns the aspect of intercellular coupling via gap junctions (26). Numerous studies have reported the presence of gap junctions between astrocytes morphologically, electrophysiologically and immunohistochemically (27-30). Gap junction proteins are encoded by a family of genes, and two of the most characterized proteins are Cx32 (31,32) and Cx43 (33). The study by Naus et al (34) showed that the mRNAs encoding these two proteins are readily detectable in the neonatal and adult brain $(35,36)$. In addition, primary cultures of astrocytes express only the Cx43 mRNA, and the level of this mRNA is significantly reduced in the glioma cells (35).

Dysregulation of gap junction coupling is a phenotypic alteration commonly observed in neoplastic cells. The studies by Bodenstine et al and Saunders et al (37-39) demonstrated a specific loss of homotypic and heterotypic GJIC in metastatic cells. While the dysregulation of GJIC in neoplastic cells is apparent, the specific signaling events and the mediators of those signaling events between malignant cells or between malignant cells and the surrounding stromal compartment appear to be largely context dependent $(40,41)$. Furthermore, restoration of GJIC appears to reduce the metastatic ability of cancer cells in certain cases $(42,43)$. The present study used the transfer dye method to detect the function of GJIC in glioma cells, and it was found that the fluorescent yellow diffusion distance was short, indicating that the cell gap junction communication function is weak, which may be one of the reasons for its aggressive nature.

The COX-2 inhibitor aspirin was used to treat the C6 cells. The results showed that the expression of COX-2 and PGE2 were significantly decreased, and the 30 and 60 min treatments reduced the levels the most, respectively, suggesting that aspirin may inhibit the synthesis of PGE2 by inhibiting of COX-2. The expression of the CX43 protein was shown to be the highest at 120 min of treatment, while the GJIC function of the glioma cells was the strongest, and the fluorescent yellow diffusion distance increased. At this time, the glioma invasion was the lowest. This indicates that aspirin can enhance the function of GJIC by inhibiting the expression of PGE2, which can decrease the invasion of glioma.

In conclusion, the biochemical mechanism of the aspirin-induced glioma invasion decrease is complex. The present results showed that one of the possibilities may be through the PGE2/GJIC signal pathway. This study further proved that if the ability of the glioma cells to synthesize PEG2 is eliminated, then the GJIC function can effectively be enhanced. Treatment of patients with a COX inhibitor that is similar to aspirin at surgery may provide more potential benefits. Although the present study is only a preliminary investigation, it indicates that the use of aspirin may make glioma therapy more effective, and may increase the survival and quality of life of the patients.

\section{Acknowledgements}

The present study was supported by the Natural Science Foundation of China (grant nos. 81101912 and 81201048), the Hebei Province Science and Technology Support Program (grant no. 152777189), and the Hebei Province Administration of Traditional Chinese Medicine, (grant no. 2014195) and the Hebei Province Department of Health and Family Planning Commission (grant no. 20150491).

\section{References}

1. Drappatz J, Schiff D, Kesari S, Norden AD and Wen PY: Medical management of brain tumor patients. Neurol Clin 25: 1035-1071, ix, 2007.

2. Cahill CM, Waterman WR, Xie Y, Auron PE and Calderwood SK: Transcriptional repression of the prointerleukin 1beta gene by heat shock factor 1. J Biol Chem 271: 24874-24879, 1996.

3. Chatterjee S, Premachandran S, Sharma D, Bagewadikar RS and Poduval TB: Therapeutic treatment with L-arginine rescues mice from heat stroke-induced death: Physiological and molecular mechanisms. Shock 24: 341-347, 2005.

4. Lan F, Yue X, Han L, Yuan X, Shi Z, Huang K, Yang Y, Zou J, Zhang J, Jiang T, et al: Antitumor effect of aspirin in glioblastoma cells by modulation of $\beta$-catenin/T-cell factor-mediated transcriptional activity. J Neurosurg 115: 780-788, 2011.

5. Ahmed R, Oborski MJ, Hwang M, Lieberman FS and Mountz JM: Malignant gliomas: Current perspectives in diagnosis, treatment, and early response assessment using advanced quantitative imaging methods. Cancer Manag Res 6: 149-170, 2014.

6. Huse JT and Holland EC: Targeting brain cancer: Advances in the molecular pathology of malignant glioma and medulloblastoma. Nat Rev Cancer 10: 319-331, 2010.

7. Nakada M, Nakada S, Demuth T, Tran NL, Hoelzinger DB and Berens ME: Molecular targets of glioma invasion. Cell Mol Life Sci 64: 458-478, 2007.

8. Phillips HS, Kharbanda S, Chen R, Forrest WF, Soriano RH, Wu TD, Misra A, Nigro JM, Colman H, Soroceanu L, et al: Molecular subclasses of high-grade glioma predict prognosis, delineate a pattern of disease progression, and resemble stages in neurogenesis. Cancer Cell 9: 157-173, 2006.

9. Louis DN, Holland EC and Cairncross JG: Glioma classification: A molecular reappraisal. Am J Pathol 159: 779-786, 2001.

10. Huang RP, Fan Y, Hossain MZ, Peng A,Zeng ZL and Boynton AL: Reversion of the neoplastic phenotype of human glioblastoma cells by connexin 43 (cx43). Cancer Res 58: 5089-5096, 1998.

11. Soroceanu L, Manning TJ Jr and Sontheimer H: Reduced expression of connexin-43 and functional gap junction coupling in human gliomas. Glia 33: 107-117, 2001.

12. $\mathrm{Pu} \mathrm{P}, \mathrm{Xia} \mathrm{Z}, \mathrm{Yu} \mathrm{S}$ and Huang Q: Altered expression of $\mathrm{Cx} 43$ in astrocytic tumors. Clin Neurol Neurosurg 107: 49-54, 2004.

13. Mesnil M, Crespin S, Avanzo JL and Zaidan-Dagli ML: Defective gap junctional intercellular communication in the carcinogenic process. Biochim Biophys Acta 1719: 125-145, 2005.

14. Honn KV, Bockman RS and Marnett LJ: Prostaglandins and cancer: A review of tumor initiation through tumor metastasis. Prostaglandins 21: 833-864, 1981.

15. Levine L: Arachidonic acid transformation and tumor production. Adv Cancer Res 35: 49-79, 1981.

16. Bockman RS: Prostaglandins in cancer: A review. Cancer Invest 1: 485-493, 1983.

17. Weissmann G: Aspirin. Sci Am 264: 84-90, 1991.

18. Vane JR: Inhibition of prostaglandin synthesis as a mechanism of action for aspirin-like drugs. Nat New Biol 231: 232-235, 1971.

19. Coussens LM, Zitvogel L and Palucka AK: Neutralizing tumor-promoting chronic inflammation: A magic bullet? Science 339: 286-291, 2013.

20. Mantovani A, Allavena P, Sica A and Balkwill F: Cancer-related inflammation. Nature 454: 436-444, 2008.

21. Rakoff-Nahoum S and Medzhitov R: Toll-like receptors and cancer. Nat Rev Cancer 9: 57-63, 2009.

22. Balkwill F, Charles KA and Mantovani A: Smoldering and polarized inflammation in the initiation and promotion of malignant disease. Cancer Cell 7: 211-217, 2005.

23. Wang D and Dubois RN: Eicosanoids and cancer. Nat Rev Cancer 10: 181-193, 2010.

24. Dannenberg AJ and Subbaramaiah K: Targeting cyclooxygenase-2 in human neoplasia: Rationale and promise. Cancer Cell 4: 431-436, 2003.

25. Castelli MG, Butti G, Chiabrando C, Cozzi E, Fanelli R, Gaetani P, Silvani V and Paoletti P: Arachidonic acid metabolic profiles in human meningiomas and gliomas. J Neurooncol 5: 369-375, 1987. 
26. Nagy JI and Rash JE: Connexins and gap junctions of astrocytes and oligodendrocytes in the CNS. Brain Res Brain Res Rev 32: 29-44, 2000

27. Gutnick MJ, Connors BW and Ransom BR: Dye-coupling between glial cells in the guinea pig neocortical slice. Brain Res 213: 486-492, 1981.

28. Kettenmann H and Ransom BR: Electrical coupling between astrocytes and between oligodendrocytes studied in mammalian cell cultures. Glia 1: 64-73, 1988

29. Dermietzel R, Traub O, Hwang TK, Beyer E, Bennett MVL, Spray DC and Willecke K: Differential expression of three gap junction proteins in developing and mature brain tissues. Proc Natl Acad Sci USA 86: 10148-10152, 1989.

30. Yamamoto T, Ochalski A, Hertzberg EL and Nagy JI: On the organization of astrocytic gap junctions in rat brain as suggested by LM and EM immunohistochemistry of connexin 43 expression. J Comp Neurol 302: 853-883, 1990.

31. Kumar NM and Gilula NB: Cloning and characterization of human and rat liver cDNAs coding for a gap junction protein. J Cell Biol 103: 767-776, 1986.

32. Paul DL: Molecular cloning of cDNA for rat liver gap junction protein. J Cell Biol 103: 123-134, 1986.

33. Beyer EC, Paul DL and Goodenough DA: Connexin43: A protein from rat heart homologous to a gap junction protein from liver. J Cell Biol 105: 2621-2629, 1987.

34. Naus CC, Belliveau DJ and Bechberger JF: Regional differences in connexin 32 and connexin43 messenger RNAs in rat brain. Neurosci Lett 111: 297-302, 1990.

35. Naus CC, Bechberger JF, Caveney S and Wilson JX: Expression of gap junction genes in astrocytes and C6 glioma cells. Neurosc Lett 126: 33-36, 1991.

36. Belliveau DJ, Kidder GM and Naus CCG: Expression of gap junction genes during postnatal neural development. Dev Genet 12: 308-317, 1991.
37. Bodenstine TM, Vaidya KS, Ismail A, Beck BH, Cook LM, Diers AR, Landar A and Welch DR: Homotypic gap junctional communication associated with metastasis suppression increases with PKA activity and is unaffected by PI3K inhibition. Cancer Res 70: 10002-10011, 2010.

38. Bodenstine TM, Vaidya KS, Ismail A, Beck BH, Diers AR, Edmonds MD, Kirsammer GT, Landar A and Welch DR: Subsets of ATP-sensitive potassium channel (KATP) inhibitors increase gap junctional intercellular communication in metastatic cancer cell lines independent of SUR expression. FEBS Lett 586: 27-31, 2012.

39. Saunders MM, Seraj MJ, Li Z, Zhou Z, Winter CR, Welch DR and Donahue HJ: Breast cancer metastatic potential correlates with a breakdown in homospecific and heterospecific gap junctional intercellular communication. Cancer Res 61: 1765-1767, 2001.

40. Kapoor P, Saunders MM, Li Z, Zhou Z, Sheaffer N, Kunze EL, Samant RS, Welch DR and Donahue HJ: Breast cancer metastatic potential: correlation with increased heterotypic gap junctional intercellular communication between breast cancer cells and osteoblastic cells. Int J Cancer 111: 693-697, 2004.

41. Li Z,Zhou Z, Welch DR and Donahue HJ: Expressing connexin 43 in breast cancer cells reduces their metastasis to lungs. Clin Exp Metastasis 25: 893-901, 2008.

42. Zhu D, Caveney S, Kidder GM and Naus CC: Transfection of C6 glioma cells with connexin $43 \mathrm{cDNA}$ : Analysis of expression, intercellular coupling, and cell proliferation. Proc Natl Acad Sci USA 88: 1883-1887, 1991

43. Martin W, Zempel G, Hülser D and Willecke K: Growth inhibition of oncogene-transformed rat fibroblasts by cocultured normal cells: Relevance of metabolic cooperation mediated by gap junctions. Cancer Res 51: 5348-5351, 1991. 